\title{
NERACA KEHIDUPAN Arthroschista hilaralis PADA TANAMAN JABON (Anthocephalus cadamba Miq)
}

\author{
(Life Table of Arthroschista hilaralis on Anthocephalus cadamba Miq) \\ Selvi Chelya Susanty, Noor Farikhah Haneda dan/and Irdika Mansur \\ Departemen Silvikultur Fakultas Kehutanan Institut Pertanian Bogor \\ Jl. Lingkar Akademik, Kampus IPB Darmaga, Bogor 16680 \\ Telp. 0251-88621677, Fax. 0251-8621677
}

Naskah masuk : 2 Desember 2013; Naskah diterima : 6 Mei 2014

\begin{abstract}
Arthroschista hilaralis is a defoliator pest which attacks Anthocephalus cadamba with a high level of damage. This study was aimed at reviewing the life table of A. hilaralis on Anthocephalus cadamba. Thirty eggs of A. hilaralis were observed until imago and egg laying stage. The parameters of population growth are gross reproductive rate (GRR), net reproductive rate (Ro), mean generation time (T), intrinsic growth rate ( $r$ ). They were calculated by using data of all the individuals hatched during the first year (lx) and the number of offspring hatched to individuals of each age $(m x)$. The results showed that GRR of A. hilaralis on A. cadamba is 141 individual per generation, Ro revealed 70 individual per female per generation, $T$ is 23.5 days, and the innate capacity for increase $(r) 0.18$ individual per female per day.
\end{abstract}

Keywords: Anthocephalus cadamba, Arthroschista hilaralis, life table

\begin{abstract}
ABSTRAK
Arthroschista hilaralis merupakan hama defoliator yang pada saat ini banyak menyerang tanaman jabon dengan tingkat kerusakan yang tinggi. Penelitian ini bertujuan untuk mengkaji neraca kehidupan A. hilaralis pada tanaman jabon (A. cadamba Miq.). Penelitian dilakukan dengan menggunakan 30 telur A. hilaralis yang dipelihara hingga menjadi imago dan bertelur kembali. Data sintasan spesifik umur $\left(1_{x}\right)$ dan keperidian spesifik umur $\left(\mathrm{m}_{\mathrm{x}}\right)$ digunakan sebagai dasar untuk menghitung parameter pertumbuhan populasi, antara lain laju reproduksi kotor (GRR), laju reproduksi bersih (Ro), rata-rata masa generasi (T), dan laju pertumbuhan instrinsik (r). Hasil penelitian menunjukkan GRR A. hilaralis adalah 141 individu/generasi, Ro sebesar 70 individu/induk/generasi, T selama 23,5 hari, dan r sebesar 0,18 individu/induk/hari. Tindakan pengelolaan hama secara berkala sangat diperlukan dalam mengontrol perkembangan hama ini, karena tingginya tingkat perkembangan dan cepatnya laju pertumbuhan $A$. hilaralis.
\end{abstract}

Kata kunci : Anthocephalus cadamba, Arthroschista hilaralis, neraca kehidupan

\section{PENDAHULUAN}

Jabon (Anthocephalus cadamba Miq.) merupakan salah satu jenis tanaman asli Indonesia yang memiliki kemampuan tumbuh yang cepat (Mansur \& Tuheteru, 2010). Tanaman ini memiliki bentuk batang yang lurus dan silindris, serta dapat digunakan untuk pembuatan kayu lapis, bahan konstruksi, bahan baku papan partikel atau bubur kertas, dan kegunaan lainnya (Mulyana \& Fahmi, 2011).

Penanaman jabon yang saat ini dilakukan secara monokultur dan dalam skala luas menyebabkan tanaman ini menjadi rentan terhadap serangan hama. Pribadi (2010) mencatat be- berapa hama defoliator menyerang tegakan jabon di Riau, antara lain Cosmoleptrus sumatranus, Coptotermes, ulat kantong (Pychidae), Dysdercus cingulatus, dan Arthroschista hilaralis. A. hilaralis merupakan hama defoliator dominan yang menyerang tanaman jabon dan menyebabkan tingkat kerusakan yang tinggi. Serangan hama ini dapat memperlambat pertumbuhan tanaman, menyebabkan terjadinya dieback (mati pucuk) dan terbentuknya cabang epikormik (Nair, 2000). Pada puncak musim kering, serangan hama ini menjadi lebih tinggi dibandingkan pada pertengahan musim kering. Pada kondisi lingkungan yang kering tanaman akan mengalami kehilangan turgiditas (kekakuan sel) se- 
hingga mudah terserang hama. Selain itu kondisi lingkungan yang kering dengan curah hujan yang rendah lebih disukai hama dan lebih menguntungkan bagi perkembangan hama (Junaedi \& Pribadi, 2011).

Informasi dasar seperti neraca kehidupan $A$. hilaralis sangat diperlukan untuk mengetahui pertumbuhan populasi serangga serta upaya pengelolaannya. Price (1997) menjelaskan bahwa neraca kehidupan merupakan ringkasan pernyataan tentang kehidupan individu-individu dalam populasi/kelompok. Tarumingkeng (1992) menambahkan bahwa neraca kehidupan dapat digunakan untuk mengkalkulasikan berbagai statistik populasi yang dapat memberikan informasi mengenai kelahiran (natalitas), kematian (mortalitas), dan peluang untuk berkembang biak, sehingga dapat digunakan sebagai parameter perilaku perkembangan populasi.

Penelitian ini bertujuan untuk mengkaji neraca kehidupan $A$. hilaralis pada tanaman jabon (A. cadamba Miq.). Informasi mengenai neraca kehidupan $A$. hilaralis diperlukan dalam rangka menelaah perubahan kepadatan dan laju pertumbuhan populasi $A$. hilaralis, sehingga dapat digunakan dalam memutuskan teknik pengelolaan hama yang sesuai.

\section{METODOLOGI}

\section{A. Waktu dan Tempat Penelitian}

Penelitian ini dilaksanakan pada bulan Juni hingga Juli 2013 di Laboratorium Entomologi Hutan, Fakultas Kehutanan, Institut Pertanian Bogor.

\section{B. Bahan dan Alat Penelitian}

Bahan yang digunakan dalam penelitian meliputi telur A. hilaralis, daun jabon (A. cadamba), kapas dan cairan madu $10 \%$ yang digunakan sebagai bahan makanan bagi imago. Alat yang digunakan dalam penelitian meliputi wadah plastik, kurungan imago dan kuas.

\section{Rancangan Penelitian dan Analisis Data}

Penelitian dilakukan dengan menggunakan 30 telur $A$. hilaralis yang diperoleh dari hasil rearing di laboratorium. Tiga puluh larva yang telah menetas dari telur tersebut kemudian dipelihara hingga menjadi pupa dan imago. Pada setiap harinya dilakukan pengamatan dan perhitungan jumlah individu yang masih hidup dan yang mengalami kematian. Pengamatan terhadap perkembangan suatu kelompok individu yang lahir pada umur yang sama (kohor) hingga kematian individu terakhir dengan mencatat kematian dan kelahiran merupakan cara untuk mendapatkan data yang menunjang pembuatan statistik dari populasi tersebut. Imago betina dan jantan yang berhasil muncul kemudian dimasukkan dalam satu kurungan agar terjadi proses kopulasi dan dilakukan perhitungan terhadap jumlah telur yang diletakkan setiap harinya.

Data mortalitas dalam pengamatan digunakan untuk menyusun neraca kehidupan A. hilaralis. Neraca kehidupan berisi data sintasan spesifik $\operatorname{umur}\left(1_{\mathrm{x}}\right)$ dan keperidian spesifik umur $\left(\mathrm{m}_{\mathrm{x}}\right)$. Berdasarkan data neraca kehidupan tersebut perhitungan dapat dilanjutkan untuk menentukan parameter-parameter pertumbuhan populasi lainnya meliputi (Price, 1984):

$$
\begin{aligned}
& R_{o} \quad=\sum 1_{\mathrm{x}} \mathrm{m}_{\mathrm{x}} \\
& \mathrm{GRR}=\sum \mathrm{m}_{\mathrm{x}} \\
& \mathrm{T}=\sum \mathrm{xl}_{\mathrm{x}} \mathrm{m}_{\mathrm{x}} / \sum \mathrm{1}_{\mathrm{x}} \mathrm{m}_{\mathrm{x}} ; \mathrm{x}=1,2,3, . . \mathrm{n} \text { hari .. } \\
& \mathrm{r}=\left(\ln \mathrm{R}_{\mathrm{o}}\right) / \mathrm{T}
\end{aligned}
$$

Keterangan:

Ro : Laju reproduksi bersih

GRR : Laju reproduksi kotor

$\mathrm{T}$ : Waktu generasi rata-rata

r : Laju pertumbuhan intrinsik

Data dalam penelitian ini diolah menggunakan software Microsoft Excel 2007, dan dianalisis secara deskriptif.

\section{HASIL DAN PEMBAHASAN}

Neraca kehidupan $A$. hilaralis digunakan untuk mengetahui tingkat perkembangan populasi A. hilaralis. Berdasarkan perhitungan neraca kehidupan dapat diperoleh informasi berbagai hal mengenai perikehidupan A. hilaralis, salah satunya kurva kesintasan (survivorship). Kurva kesintasan menggambarkan peluang individu $A$. hilaralis yang hidup pada semua stadia mulai dari telur, larva, pupa, dan imago (lx), serta keperidian dari imago betina per hari (mx). Price (1984) menjelaskan bahwa bentuk kurva survivorship ini diperlukan untuk memahami strategi reproduksi populasi dan langkah-langkah dalam pengelolaannya.

Kurva kesintasan (survivorship) A. hilaralis menunjukkan tingkat kematian yang rendah pada awal perkembangan diikuti dengan tingkat kema- 
tian yang tinggi seiring dengan bertambahnya umur. Menurut Price (1997) terdapat tiga tipe kurva keberhasilan hidup serangga di alam, yaitu tipe I, II, dan III. Kurva tipe I menggambarkan kematian organisme dalam jumlah sedikit ketika umur muda dan kematian dalam jumlah besar ketika berumur tua, tipe II menggambarkan laju kematian yang konstan, dan tipe III menggambarkan kematian yang lebih besar pada umur muda. Hasil pengamatan dari 30 serangga $A$. hilaralis menunjukkan bahwa kurva perkembangan hidup serangga ini termasuk tipe I yang memperlihatkan kematian yang tinggi pada umur tua. Morgan et al. (2001) menjelaskan bahwa neraca kehidupan dipengaruhi oleh beberapa faktor, yaitu spesies, inang, kondisi iklim tempat penelitian, dan metode perbanyakan serangga (rearing) yang digunakan. Selama penelitian rata-rata suhu pada lokasi penelitian menunjukan $27^{\circ} \mathrm{C}$ dengan kelembaban $67 \%$.

Keperidian imago betina dapat diketahui dengan cara menghitung banyaknya telur yang diletakan setiap harinya. Nilai keperidian ini dipengaruhi oleh banyaknya individu betina dalam populasi. Semakin banyak jumlah betina maka telur yang dihasilkan juga akan semakin banyak, sehingga meningkatkan jumlah serangan hama. Nilai $\mathrm{m}_{\mathrm{x}}$ menunjukkan banyaknya telur yang dihasilkan oleh imago betina yang berumur $\mathrm{x}$ hari setelah memperhitungkan nisbah kelamin. Banyaknya imago jantan dan betina yang muncul serta rata-rata jumlah telur yang dihasilkan perharinya disajikan pada Tabel 1.

Berdasarkan kurva kesintasan tampak bahwa peletakan telur $A$. hilaralis dimulai pada hari ke20 hingga hari ke-30, dan puncak peneluran terjadi pada hari ke-25 dengan rata-rata jumlah telur yang diletakkan sebanyak 24 butir (Gambar 1). Velasco \& Walter (1993) menyatakan bahwa keberhasilan perkembangan serangga dan fase reproduktif serangga sangat dipengaruhi oleh kualitas makanan.

Hasil perhitungan neraca kehidupan A. hilaralis meliputi laju reproduksi kotor (GRR), laju reproduksi bersih (Ro), lama generasi $(\mathrm{T})$, dan laju pertambahan intrinsik (r) ditampilkan pada Tabel 2.

Tabel(Table) 1. Jumlah imago jantan dan betina, serta rata-rata telur yang dihasilkan setiap harinya (The number of male and female adult, and the average of eggs produced each day)

\begin{tabular}{|c|c|c|c|c|c|c|c|}
\hline (Day) & $\begin{array}{l}\text { Imago jantan } \\
\text { (Adult male) }\end{array}$ & $\begin{array}{c}\text { Imago } \\
\text { betina } \\
(\text { Adultfemale })\end{array}$ & $\begin{array}{c}\text { Rata-rata jumlah } \\
\text { telur/hari } \\
\text { (Average number } \\
\text { of eggs/day ) }\end{array}$ & $\begin{array}{l}\text { Hari } \\
\text { (Day) }\end{array}$ & $\begin{array}{l}\text { Imago } \\
\text { jantan } \\
(\text { Adult } \\
\text { male })\end{array}$ & $\begin{array}{l}\text { Imago } \\
\text { betina } \\
\text { (Adult } \\
\text { female) }\end{array}$ & $\begin{array}{l}\text { Rata-rata } \\
\text { jumlah } \\
\text { telur/hari } \\
\text { (Average } \\
\text { number of } \\
\text { eggs/day) }\end{array}$ \\
\hline 1 & 0 & 0 & 0 & 17 & 0 & 0 & 0 \\
\hline 2 & 0 & 0 & 0 & 18 & 1 & 1 & 0 \\
\hline 3 & 0 & 0 & 0 & 19 & 1 & 4 & 0 \\
\hline 4 & 0 & 0 & 0 & 20 & 3 & 2 & 6 \\
\hline 5 & 0 & 0 & 0 & 21 & 1 & 3 & 10 \\
\hline 6 & 0 & 0 & 0 & 22 & 3 & 1 & 15 \\
\hline 7 & 0 & 0 & 0 & 23 & 3 & 1 & 13 \\
\hline 8 & 0 & 0 & 0 & 24 & 0 & 0 & 23 \\
\hline 9 & 0 & 0 & 0 & 25 & 1 & 0 & 24 \\
\hline 10 & 0 & 0 & 0 & 26 & 0 & 0 & 15 \\
\hline 11 & 0 & 0 & 0 & 27 & 0 & 0 & 10 \\
\hline 12 & 0 & 0 & 0 & 28 & 0 & 0 & 7 \\
\hline 13 & 0 & 0 & 0 & 29 & 0 & 0 & 13 \\
\hline 14 & 0 & 0 & 0 & 30 & 0 & 0 & 6 \\
\hline 15 & 0 & 0 & 0 & 31 & 0 & 0 & 0 \\
\hline 16 & 0 & 0 & 0 & & & & \\
\hline
\end{tabular}




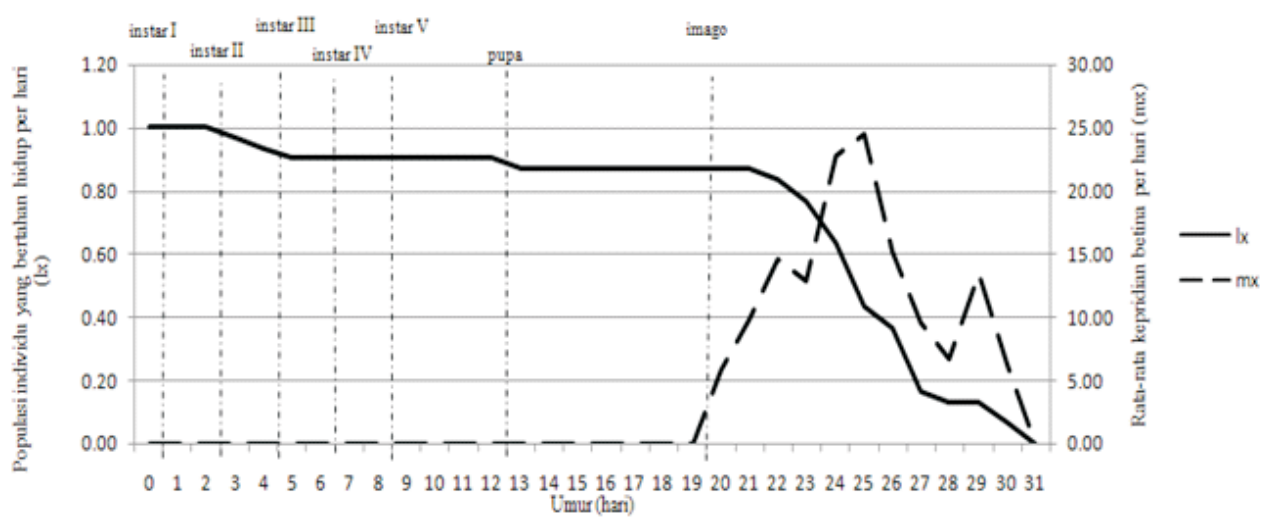

Gambar(Figure) 1. Kurva kesintasan Arthroschista hilaralis (Survivorship curve of Arthroschista hilaralis)

Tabel (Table) 2. Neraca kehidupan Arthroschista hilaralis (Life table of Arthroschista hilaralis)

\begin{tabular}{lcl}
\hline $\begin{array}{c}\text { Parameter populasi } \\
\text { (Population parameters) }\end{array}$ & $\begin{array}{c}\text { Nilai } \\
(\text { Value })\end{array}$ & \\
\hline Laju reproduksi kotor (GRR) & 141 & individu/generasi \\
Laju reproduksi bersih (Ro) & 70 & individu/induk/generasi \\
Waktu generasi rata-rata (T) & 23,5 & Hari \\
Laju pertumbuhan intrinsik (r) & 0,18 & individu/induk/hari \\
\hline
\end{tabular}

GRR menggambarkan rataan jumlah keturunan betina per induk yang dihasilkan oleh individu $A$. hilaralis yang hidupnya mencapai umur maksimal. Nilai GRR A. hilaralis sebesar 141 menunjukkan bahwa $A$. hilaralis mampu menghasilkan keturunan sebesar 141 individu per induk per generasi.

Nilai Ro menunjukkan rata-rata banyaknya keturunan yang dihasilkan oleh seekor induk betina setiap generasi setelah memperhitungkan kematian atau peluang hidup (lx) dari $A$. hilaralis. Nilai Ro $>1$ menggambarkan bahwa pada generasi berikutnya populasi akan mengalami peningkatan. Lebih lanjut Price (1997) menjelaskan bahwa suatu populasi dikatakan stabil bila $\mathrm{Ro}=0$, tetapi bila $\mathrm{Ro}>1$ populasi akan bertambah dan bila Ro $<1$ populasi akan berkurang. Nilai Ro A. hilaralis sebesar 70 individu/ induk/generasi menggambarkan bahwa pada keadaan lingkungan tersebut populasi $A$. hilaralis akan meningkat 70 kali populasi generasi sebelumnya. Tingginya angka pertumbuhan serangga apabila berada pada kondisi lingkungan yang optimum dapat menyebabkan serangga tersebut dapat cepat berkembang menjadi wabah.
Nilai rata-rata masa generasi ( $\mathrm{T}$ ) menggambarkan waktu yang dibutuhkan sejak telur diletakkan sampai saat imago betina yang berasal dari telur tersebut menghasilkan keturunannya. Nilai $\mathrm{T}$ yang semakin kecil menunjukkan semakin cepat suatu organisme untuk berkembang biak. Nilai $\mathrm{T} A$. hilaralis sebesar 23,5 menunjukkan bahwa dalam waktu 23,5 hari induvidu betina $A$. hilaralis mampu menghasilkan keturunan kembali. Berdasarkan nilai tersebut dapat diperkirakan bahwa dalam satu tahun $A$. hilaralis mampu menghasilkan 15 generasi. Thapa dan Bhandari (1976) menjelaskan bahwa A. hilaralis di West Bengal India dalam satu tahun $A$. hilaralis manghasilkan 11-12 generasi. Perbedaan jumlah generasi yang dihasilkan dalam penelitian dengan Thapa (1976) dapat disebabkan karena adanya perbedaan kondisi lingkungan (suhu dan kelembaban) antara lokasi penelitian. Kondisi lingkungan mempengaruhi lamanya perkembangan serangga. Atmosoedarjo et al. (2000) menyebutkan bahwa pertumbuhan serangga biasanya lebih cepat pada temperature yang lebih tinggi. Lebih jauh Wigglesworth (1972) menjelaskan bahwa perbedaan suhu, nutrisi makanan, 
kelembaban udara akan mempengaruhi perkembangan serangga selama siklus hidupnya.

Laju pertambahan intrinsik (r) merupakan pertambahan populasi pada lingkungan konstan dan sumberdaya yang tidak terbatas (Birch 1948). Nilai laju pertambahan intrinsik (r) menggambarkan pertambahan populasi pada lingkungan konstan dan sumberdaya yang tidak terbatas. Nilai yang diperoleh ditentukan oleh berbagai aspek yang berhubungan dengan siklus kehidupan organisme tersebut, yaitu kematian, kelahiran, dan waktu perkembangan. Nilai $\mathrm{r} A$. hilaralis sebesar 0,18 menunjukkan bahwa tingkat kematian lebih rendah dibandingkan dengan tingkat kelahiran. Dengan nilai $\mathrm{r}$ sebesar 0.18 menunjukkan adanya peningkatan populasi $A$. hilaralis sebanyak 0,18 individu/induk pada setiap periode kelas umur. Brewer (1979) menjelaskan bahwa tinggi rendahnya nilai $r$ dipengaruhi oleh jumlah keturunan per periode perkembangan, jumlah yang bertahan hidup dan selama masa reproduktif, usia saat reproduktif dimulai, dan lama usia reproduktif.

Neraca kehidupan bukanlah nilai akhir dari analisis dinamika populasi, tetapi memberikan informasi penampilan sistematik dari data ketahanan hidup, mortalitas dan kemampuan bereproduksi dalam populasi. Fungsi utama dari neraca kehidupan adalah untuk memberikan deskripsi tentang kemampuan hidup suatu serangga pada kondisi lingkungan tertentu (Harcourt, 1969).

Perhitungan neraca kehidupan A. hilaralis menunjukan tingginya tingkat perkembangan populasi dari A. hilaralis. A. hilaralis berpotensi menjadi hama utama (main pests) tanaman jabon karena memiliki kemampuan perkembangan populasi yang tinggi dan laju pertumbuhan yang cepat. Oleh karena itu tindakan pengelolaan hama secara berkala sangat diperlukan dalam mengontrol perkembangan hama ini.

\section{KESIMPULAN DAN SARAN}

Neraca kehidupan A. hilaralis menunjukkan laju reproduksi kotor (GRR) A. hilaralis sebesar 141 individu/generasi, laju reproduksi bersih (Ro) 70 individu/induk/ generasi, rata-rata masa generasi (T) 23,5 hari, dan laju pertambahan instrinsik (r) 0,18 individu/induk/hari. Tindakan pengelolaan hama secara berkala sangat diperlukan dalam mengontrol perkembangan dari ha- ma ini, karena tingginya tingkat perkembangan dan cepatnya laju pertumbuhan hama $A$. hilaralis.

\section{DAFTAR PUSTAKA}

Atmosoedarjo, S., Kartasubrata, J., Kaomini, M., Saleh, W., Moerdoko, W. (2000). Sutera Alam Indonesia. Bandung:Yayasan Sarana Wanajaya. 337 hal.

Birch, L.C. (1948). The intristic rate of natural increase of an insect population. The Journal of Animal Ecology 17:15-26.

Brewer, R. (1979). Principles of ecology. Phidelphia (US). W.B Sounders Co. $299 \mathrm{p}$.

Harcourt, D.G. (1969). The development of life tables in the study of natural insect populations. Annu. Rev. Entomol. 14: 175-191.

Junaedi, A., Pribadi, A. 2011. Hubungan antara Hama Daun Arthroschista hilaralis dengan Aspek Iklim dan Pertumbuhan Pohon Jabon. Laporan hasil penelitian. Kuok Riau: Balai Penelitian Teknologi Serat Tanaman Hutan. Balai Penelitian Teknologi Serat Tanaman Hutan.

Mansur, I., Tuheteru D. (2010). Kayu Jabon. Jakarta: Penebar Swadaya. 118 hal.

Mulyana, D., Fahmi, I. (2011). Panduan lengkap bisnis dan bertanam kayu jabon. Jakarta: Agromedia. 142 hal.

Morgan, D., Walters, K.F.A., Aegerter, J.N. (2001). Effect of temperatur and cultivar on pea aphid, Acyrthosiphon pisum (Hemiptera: Aphididae) life history. Bulletin of Entomological Research 91:47-52.

Nair, K.S.S. (2000). Insect pest and diseases in Indonesian Forest: An assesment of the major threats, Research Efforts and Literature. Bogor: CIFOR. $101 \mathrm{p}$.

Pribadi, A. (2010). Serangan hama dan tingkat kerusakan daun akibat hama defoliator pada tegakan jabon (Anthocephalus cadamba Miq.). Jurnal Penelitian Hutan dan Konservasi Alam 7(4): 451-458

Price, P.W. (1984). Insect ecology. Ed $2^{\text {nd }}$. Canada: John Wiley and Sons. 607 p.

Price, P.W. (1997). Insect ecology. Ed 32 ${ }^{\text {rd }}$. New York: John Wiley. p: 474-511.

Tarumingkeng, R.C. (1992). Dinamika Pertumbuhan Populasi Serangga. Bogor: Pusat Antar Universitas Ilmu Hayat Institut Pertanian Bogor (IPB). 201 hal.

Thapa, R.S., \& Bhandari, R.S. (1976). Biology, ecology and control of kadam defoliator, Arthroschista hilaralis Walk. (Lepidoptera: 
Pyralidae) in plantation in West Bengal. Indian For. 102 (6): 333-401.

Velasco, L.R.I., Walter, G.H. (1993). Potential of host switching in Nezara viridula (Hemiptera: Pentatomidae) to enhance survival and reproduction. Environmental Entomology 22: 327-333.

Wigglesworth, W.B. (1972). The priciple of insect physiology. London: Mathuen and Co. Ltd. 444 p) 